\title{
Using Retouch-Free Disclaimers in Advertisements to Reduce Negative Social Comparison in Adolescents
}

\author{
Galen Heuer ${ }^{1}$ and Jill Berge ${ }^{1 \#}$ \\ ${ }^{1}$ Lake Washington High School, Kirkland, WA, USA \\ "Advisor
}

ABSTRACT

This experimental study examines the effects of retouch-free disclaimers in advertising on adolescents' mood, selfesteem, and how authentic the ad is perceived to be. These effects were compared to those of adolescents who viewed ads with a traditional retouched disclaimer, and those of adolescents who viewed ads with no disclaimer at all. I found no significant correlations between type of disclaimer and change in mood or self-esteem. However, adolescent females did view ads with a retouch-free disclaimer as significantly more authentic than ads with a retouched disclaimer. Additionally, I found that adolescent females found all advertisements, regardless of experimental condition, to be significantly more authentic than their male peers did. This study can provide guidance to fashion and beauty marketers on the potential benefits of using retouch-free disclaimers to appeal to an adolescent audience.

\section{Retouching in advertising, its impacts, and possible solutions}

\subsection{Impacts of digital retouching in advertising}

The foundational basis for most research investigating the impacts of advertising on self-esteem comes from Festinger's 1954 theory of social comparison. The theory states that people use comparison to others as a way of assessing their own self-worth, whether the comparison be upward to someone who they perceive as "better" than them, or downward to someone they perceive as "worse". One example of this social comparison is in advertising, especially advertising that is designed to make the viewer feel as though they aren't good enough or need a product to look/feel better. Negative social comparison is made even more extreme when models' faces or bodies are digitally retouched using Photoshop or other similar software (Giorgianni et. al, 2020; Groesz et. al, 2002). Festinger's theory applies to retouching because individuals compare themselves to models in advertising, and if the models are retouched to appear more attractive, the viewer's comparison will be more upward as a result. Social comparison can be positive when the viewer uses the object of their comparison as motivation. However, it can also have pernicious mental health consequences when the viewer's self-esteem is lowered.

The recent increase of photo manipulation has led researchers to examine the consequences that this digital deception has on younger audiences. According to Prabhu and D'Cunha's study of 309 adolescents (2018), over 90\% had some form of concerns about their body shape, regardless of BMI or gender. Additionally, those with higher rates of body dissatisfaction were more likely to have low self-esteem. This common concern and the negative mental health effects that it perpetrates (Roeder, 2015) is only exacerbated by unrealistic standards set by edited photos of models in the media. Adolescent girls are especially affected by exposure to retouched images, reporting more concern with appearance, pressure to meet the media's body standards, and greater objectified body consciousness than males of the same age group (Harrison \& Hefner, 2014). 


\subsection{Solutions to negative social comparison as a result of digital retouching}

There are a few methods that have so far been attempted to remedy this issue. The first is individual companies committing to eliminating retouching and using models with a wider range of sizes in their advertisements. Such companies include Aerie Lingerie, Dove, and ASOS. But even in more inclusive advertising campaigns, there can still be negative social comparison from viewers to models (Runfola et. al, 2013). The second is government legislation being passed to require disclaimers on advertisements where a model has been retouched to appear thinner, theoretically interrupting the social comparison processes by making the model a less credible target for comparison. Countries that have taken this major action include Israel and France (Ho-Young, 2019; Taylor et. al, 2018). However, there is evidence that disclaimers may not have any impact on how people perceive retouched images. In fact, being aware of retouching on an image of a model can actually increase the perceived attractiveness of the model to viewers (Harrison \& Hefner, 2014) or increase the occurrence of negative thoughts (Selimbegovic \& Chatard, 2015; MacCallum $\&$ Widdows, 2018), creating the opposite of the intended effect. This could have been because the mere mention of retouching primed subjects to think about physical appearance, and thus their own perceived attractiveness. Or it could have been because the disclaimers added an element of legitimacy and credibility to the retouched images, which were of everyday people and not models.

Despite adolescents' particular susceptibility to negative body image and self-esteem based on unrealistic media (Kerr, 2010), many studies focus on examining only an adult population's perception of disclaimers on retouched images. However, one study by Paraskeva and colleagues (2016) indicates that there are significant differences between adults and adolescents on the issue. When Paraskeva and colleagues surveyed British consumers aged from 11 to 78, they found that adults were much more skeptical about the effectiveness of retouching disclaimers as preventors of negative body image than adolescents were. Adolescent girls in particular ranked disclaimers as one of the most helpful strategies for promoting a healthy body image in advertising. This justifies further research on the impacts of retouching disclaimers on an adolescent population, since they clearly have different personal opinions on their effectiveness and therefore could have different emotional and mental responses when exposed to them.

\subsection{Retouch-free disclaimers}

Returning to the foundational theory of social comparison, researchers Cornelis and Peter hypothesized that a "retouch-free" disclaimer would help stimulate beneficial downward comparison rather than harmful upward comparison in the viewer (2017). A retouch free disclaimer is different than a retouched disclaimer in that it states that the model in the photo has not been retouched rather than stating that they have. In their study, Cornelis and Peter surveyed women's mood, body satisfaction, and perceived effectiveness of the ad after viewing the same ad with no disclaimer, a retouched disclaimer, or a retouch-free disclaimer. They found that Millennial women did in fact have higher body satisfaction after viewing advertisements with a retouch-free disclaimer when compared to women who viewed an advertisement with a traditional disclaimer or an advertisement with no disclaimer at all. This positive effect was proven through a second study by Cornelis and Peter to be mediated by the perceived authenticity of the ad, categorized by the way viewers judged the realness of the model in the ad as well as the meaningfulness of the ad's overall message. Since authenticity was shown to be key value for the Millennial age group, this study offers one way that brands could appeal more to Millennials as well as reduce the potentially unethical practice of retouching.

Since retouch-free disclaimers are a relatively new concept, there have been no studies on their impacts with an adolescent population under the age of 18 . These findings would be significant because adolescents have been shown to be especially, if not the most, susceptible age group to negative social comparison, body dissatisfaction, and low self-esteem. They also represent a key part of many brands' customer demographics, making them a substantial consumer group that many advertisements are targeting, including advertisements that use retouching. Therefore, a study that examines how adolescents respond to retouch-free disclaimers could be beneficial not just in reducing the 
mental health consequences of unrealistic beauty standards for adolescents, but in allowing brands to potentially refine their marketing strategies and be perceived as more authentic by this important population.

\section{Methods}

An experimental method was chosen to examine the impacts of retouch-free disclaimers in a simulated real-life scenario. In the experiment, participants viewed a retouch-free disclaimer on a typical fashion advertisement and the changes in their mood and self-esteem were compared to those of participants who viewed an ad with a retouching disclaimer, and those who viewed an ad with no disclaimer at all.

The majority of the methodology for this study was based on the methods of Studies 1 and 2 within a similar project by Cornelis and Peter (2017), with a few exceptions. Study 1 examined the impacts of retouch-free disclaimers on mood and self-esteem/body satisfaction, whereas Study 2 investigated the underlying causes of these impacts and found perceived authenticity of the ad to be the correlating factor with mood and self-esteem. In this study, Cornelis and Peter's first and second studies were combined for the purpose of surveying impacts on mood and self-esteem simultaneously with impacts on participants' perception of the ad that the prior two variables were found to be correlated with. The studied demographic was changed from adults to adolescents in order to align with the research purpose of examining the effects of retouch-free disclaimers on an adolescent population. I used both male and female participants for my experiment, rather than Cornelis and Peter's all-female sample, because I could find no prior research on how a male population responds to retouch-free disclaimers, much less a male adolescent population. Additionally, a few survey questions from Cornelis and Peter's method were eliminated by a pretest conducted with seven female adolescent participants to identify any redundancies in participant answers.

One hundred forty-eight male and female participants at a midsize, public high school in Kirkland, Washington were recruited for the study based on their enrollment in marketing classes. They were offered incentives of nominal value in the form of extra credit points by marketing teachers. All participants were between the ages of 14 and 18. The survey was given in an online format, and participants were encouraged to take the entire survey in one session and to avoid outside distractions. Students were not observed while they were completing the survey. The full list of survey questions can be found in Appendix B.

After reading about the basic details of the study and giving informed consent, participants were surveyed on mood using three items on a ten-point scale ranging from "not at all" to "extremely" (ex. How happy do you feel right now?) that were taken directly from the questionnaire described in Cornelis and Peter's study. Participants were surveyed on self-esteem using eight items on a five-point Likert scale (ex. I am able to do things as well as most other people), which were also taken from Cornelis and Peter. Lastly, participants were surveyed on body image with ten items on a five-point Likert scale (ex. I often compare my appearance to others'). Three of these were taken from Cornelis and Peter, and the remainder were devised by the researcher.

Next, participants were shown one of the three ad conditions: an ad with a retouched disclaimer (The model in this ad has been retouched), an ad with a retouch-free disclaimer (The model in this ad has NOT been retouched), or a control condition with an ad with no disclaimer at all. The ad shown to each participant was selected from the three conditions based on the first letter of the participant's first name (ex. names starting with A-H were shown the control condition) in order to randomize the ad each participant was shown. The gender of the model in the stimulus ad corresponded with the gender of the participant in order to create most effective circumstances for social comparison (Harrison \& Hefner, 2014); as well as to replicate the fact that only female participants were used with a female model in Cornelis and Peter's study. Initially, the same image from Cornelis and Peter's study was to be used in this study's advertising stimuli. However, that image could be considered inappropriate for a younger audience and for materials distributed in a school environment. Therefore, two new images were found online (one with a female model and one with a male model) and labelled with the corresponding disclaimers to be used as stimuli. To most closely replicate the image used in Cornelis and Peter's study, both of the chosen models were of Caucasian descent, looked to be in their mid-to-late-twenties, and were smiling joyfully and looking at the camera. Each of the models was 
photographed from the waist up using a high-quality camera and posed in a candid style, factors that were carefully considered in order to minimize confounding of variables such as viewer mood and perceived authenticity. Additionally, each ad was labeled with the fake brand logo ANEA. This logo and brand name was found to register no familiarity or bias with the participants in Cornelis and Peter's study. Each ad used in this study can be viewed in Appendix A.

Participants were instructed to spend between 10 and 15 seconds viewing the advertisement so that their initial and honest impressions of the ad could be captured most accurately, and to mimic the short viewing time of advertisements in a real-world setting. After exposure to one of the three ad conditions, participants were re-surveyed on mood and self-esteem as well as the authenticity of the ad. This last variable was measured by four questions on a ten-point scale ranging from "not at all" to "extremely" (ex. "How meaningful is this ad to you?"). The participants were then thanked for their time and participation and again prompted to contact the researcher with any questions or concerns.

\section{Results}

\subsection{Characteristics of the sample}

Before calculating any results, I checked that the females in my sample $(\mathrm{N}=76)$ did not vary too significantly in prior mood or self-esteem; and did the same for the males $(\mathrm{N}=72)$. The use of one-way analyses of variance (ANOVAs) showed that the males across the three experimental groups did not differ significantly in prior mood $(p=0.902)$ or self-esteem $(p=0.158)$. Using the same process for females across the three experimental groups, I found that they also did not differ significantly in prior mood $(p=0.522)$ or self-esteem $(p=0.578)$. This is important because it shows that there were no extreme outliers in terms of mood or self-esteem in my sample that could potentially throw off the results of the experiment.

Each participant was given scores for pre- and post- exposure mood, pre- and post- exposure self-esteem, and perceived authenticity of the ad. Scores for mood and perceived authenticity ranged from 0 to 10 , and scores for self-esteem were calculated based on participant's Likert scale ratings and ranged from -36 (lowest self-esteem) to 36 (highest self-esteem). The scores for change in mood and change in self-esteem were calculated by subtracting each participant's pre-exposure scores from their post-exposure scores in each category. The mean scores for change in mood $(\triangle \mathrm{MOOD})$, change in self-esteem $(\Delta \mathrm{SE})$, and perceived authenticity (PA) sorted by gender and experimental group can be found in Table 1 .

Table 1. Mean results for change in mood, change in self-esteem, and perceived authenticity of the ad for male and female participants.

\begin{tabular}{|l|l|l|l|l|l|l|}
\hline Gender & \multicolumn{2}{|l}{ Male } & \multicolumn{2}{l|}{ Female } \\
\hline $\begin{array}{l}\text { Advertising } \\
\text { Condition }\end{array}$ & $\Delta$ MOOD & $\Delta$ SE & PA & $\Delta$ MOOD & $\Delta$ SE & PA \\
\hline Control & -0.51 & 0.39 & 3.02 & -0.17 & -0.19 & 4.09 \\
\hline Retouch-free & -0.19 & 0.21 & 3.39 & -0.04 & 1.50 & 5.13 \\
\hline Retouched & -0.11 & 1.12 & 3.19 & -0.14 & 0.43 & 3.69 \\
\hline Average & -0.27 & 0.57 & 3.20 & -0.12 & 0.58 & 4.30 \\
\hline
\end{tabular}




\subsection{Results for male change in mood}

The results of the experiment showed varying effects on the mood of male participants, controlling for initial mood. Further $\mathrm{t}$-testing showed that the retouch-free condition $(\mathrm{M}=-0.19)$ did not lead to a significantly more extreme change in mood than the retouched condition $(\mathrm{M}=-0.11)(\mathrm{t}=-0.441, p=0.661)$ or control condition $(\mathrm{M}=-0.51)(\mathrm{t}=$ $1.432, p=0.159)$. The retouched and control conditions also did not differ significantly from each other $(\mathrm{t}=1.756, p$ $=0.086)$. These results are illustrated in Figure 1 .

\subsection{Results for female change in mood}

The results of the experiment showed varying effects on the mood of female participants, controlling for initial mood. Further t-testing showed that the retouch-free condition $(M=-0.04)$ did not lead to a significantly more extreme change in mood than the retouched condition $(\mathrm{M}=-0.14)(\mathrm{t}=0.304, p=0.762)$ or control condition $(\mathrm{M}=-0.17)(\mathrm{t}=$ $0.443, p=0.660)$. The retouched and control conditions also did not differ significantly from each other $(\mathrm{t}=0.117, p$ $=0.908)$. These results are illustrated in Figure 1 .

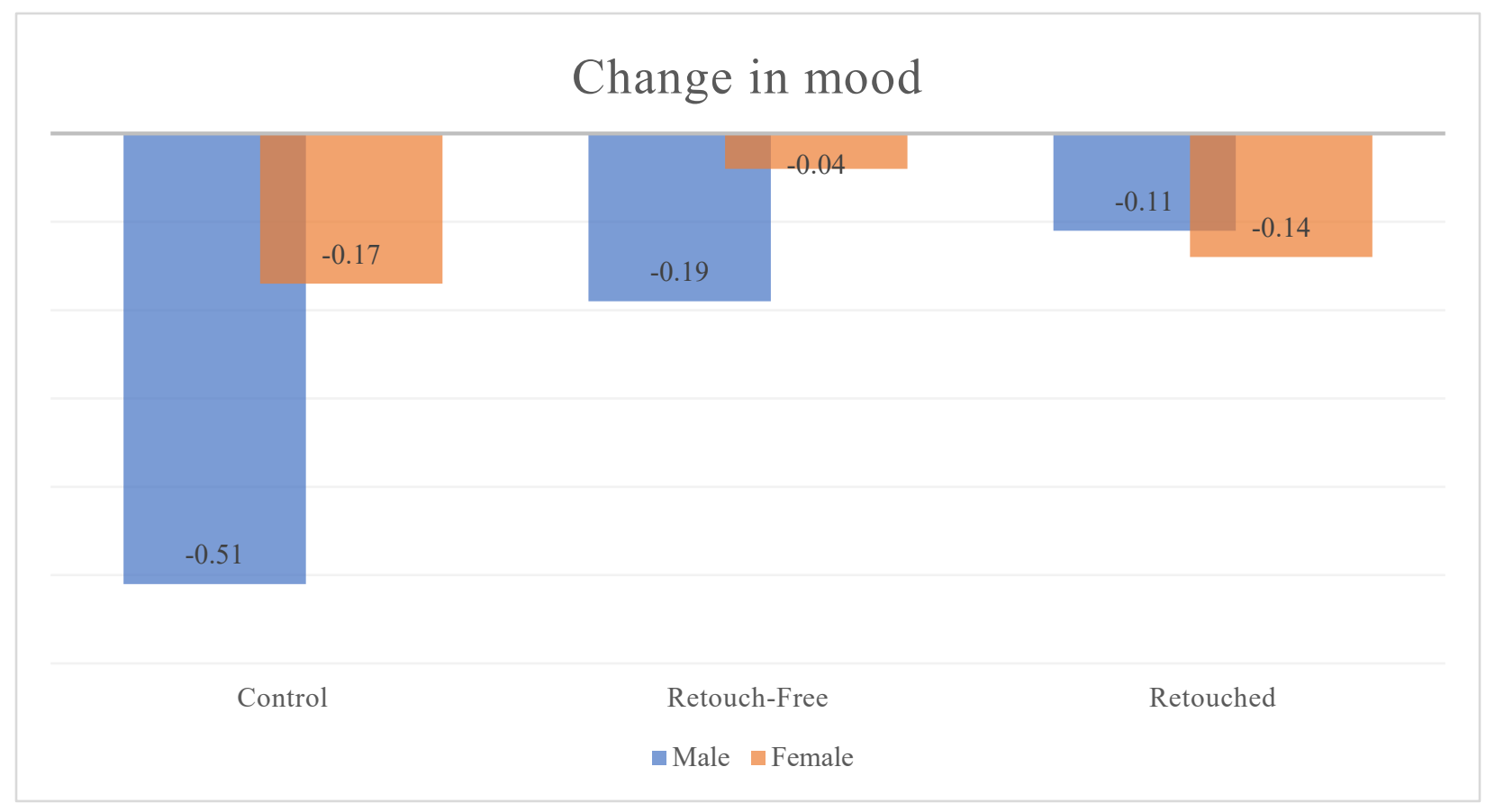

Figure 1. Average change in mood (post-exposure score - pre-exposure score) in male and female participants across the three experimental conditions.

\subsection{Results for male self-esteem}

The results of the experiment showed varying effects on the self-esteem and appearance satisfaction of male participants, controlling for initial self-esteem. Further t-testing showed that the retouch-free condition $(\mathrm{M}=0.21)$ did not lead to a significantly higher mood than the retouched condition $(\mathrm{M}=1.12)(\mathrm{t}=-0.891, p=0.378)$ or control condition $(\mathrm{M}=0.39)(\mathrm{t}=-0.165, p=0.869)$. The retouched and control conditions also did not differ significantly from each other $(\mathrm{t}=-0.615, p=0.542)$. These results are illustrated in Figure 2. 


\subsection{Results for female self-esteem}

The results of the experiment showed varying effects on the self-esteem and appearance satisfaction of female participants, controlling for initial self-esteem. Further t-testing showed that the retouch-free condition $(\mathrm{M}=1.50)$ did not lead to a significantly higher mood than the retouched condition $(\mathrm{M}=0.43)(\mathrm{t}=0.865, p=0.392)$ or control condition $(\mathrm{M}=-0.19)(\mathrm{t}=1.502, p=0.141)$. The retouched and control conditions also did not differ significantly from each other $(\mathrm{t}=-0.678, p=0.502)$. These results are illustrated in Figure 2.

\section{Change in self-esteem}

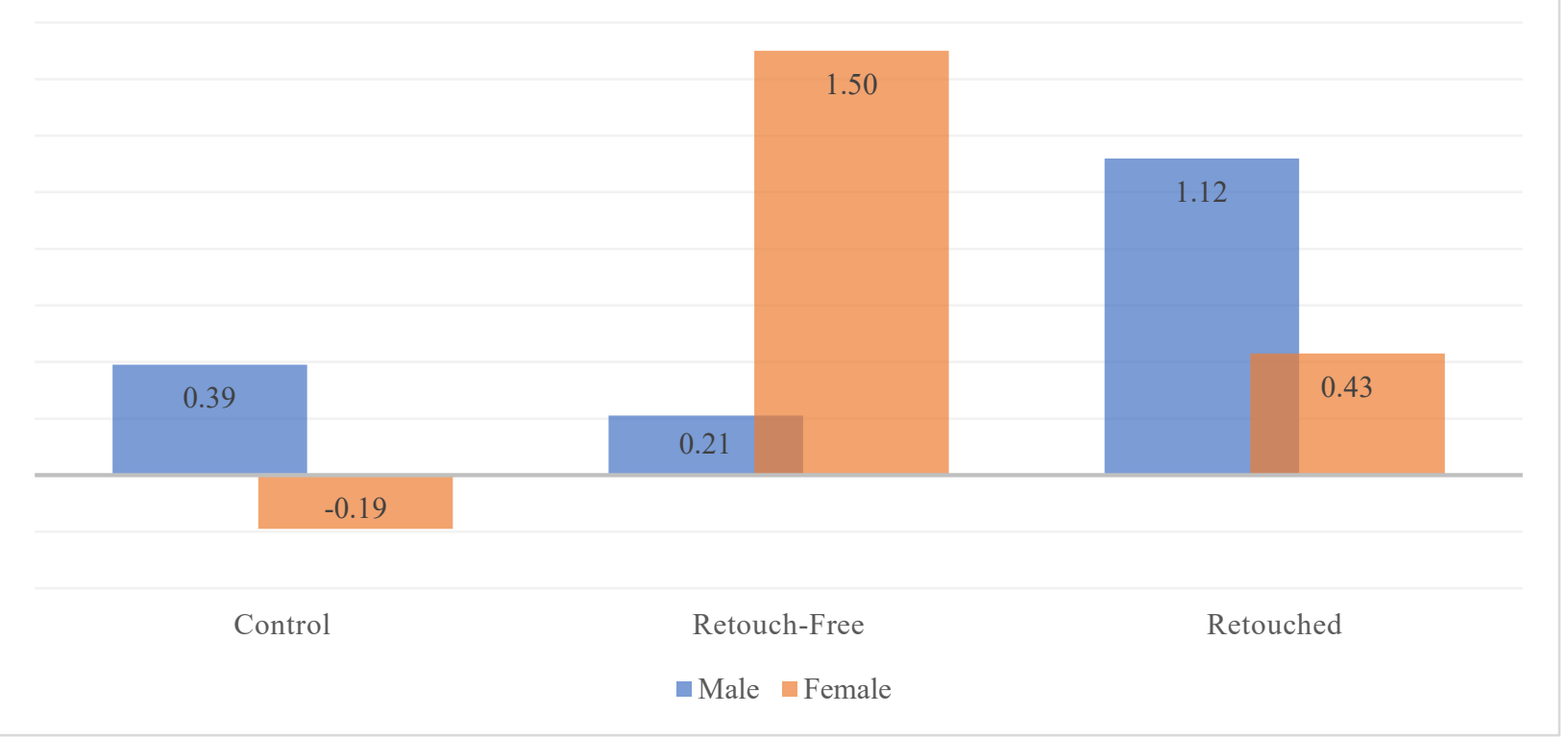

Figure 2. Average change in self-esteem (post-exposure score - pre-exposure score) in male and female participants across the three experimental conditions.

\subsection{Results for male perceived authenticity}

The results of the experiment showed varying effects on how male participants perceived authenticity of the ad. Further t-testing showed that the retouch-free condition $(\mathrm{M}=3.39)$ did not lead to a significantly higher perceived authenticity than the retouched condition $(\mathrm{M}=3.19)(\mathrm{t}=0.449, p=0.656)$ and control condition $(\mathrm{M}=3.02)(\mathrm{t}=0.837$, $p=0.407)$. The retouched and control conditions also did not differ significantly from each other $(\mathrm{t}=-0.356, p=$ 0.724). These results are illustrated in Figure 3.

\subsection{Results for female perceived authenticity}

The results of the experiment showed varying effects on how female participants perceived authenticity of the ad. Further t-testing showed that the retouch-free condition $(\mathrm{M}=5.13)$ led to a significantly higher perceived authenticity than the retouched condition $(\mathrm{M}=3.69)(\mathrm{t}=2.635, p=0.012)$, but not significantly higher than the control condition $(\mathrm{M}=4.09)(\mathrm{t}=1.799, p=0.078)$. The retouched and control conditions did not differ significantly from each other $(\mathrm{t}$ $=0.757, p=0.453)$. These results are illustrated in Figure 3 . 


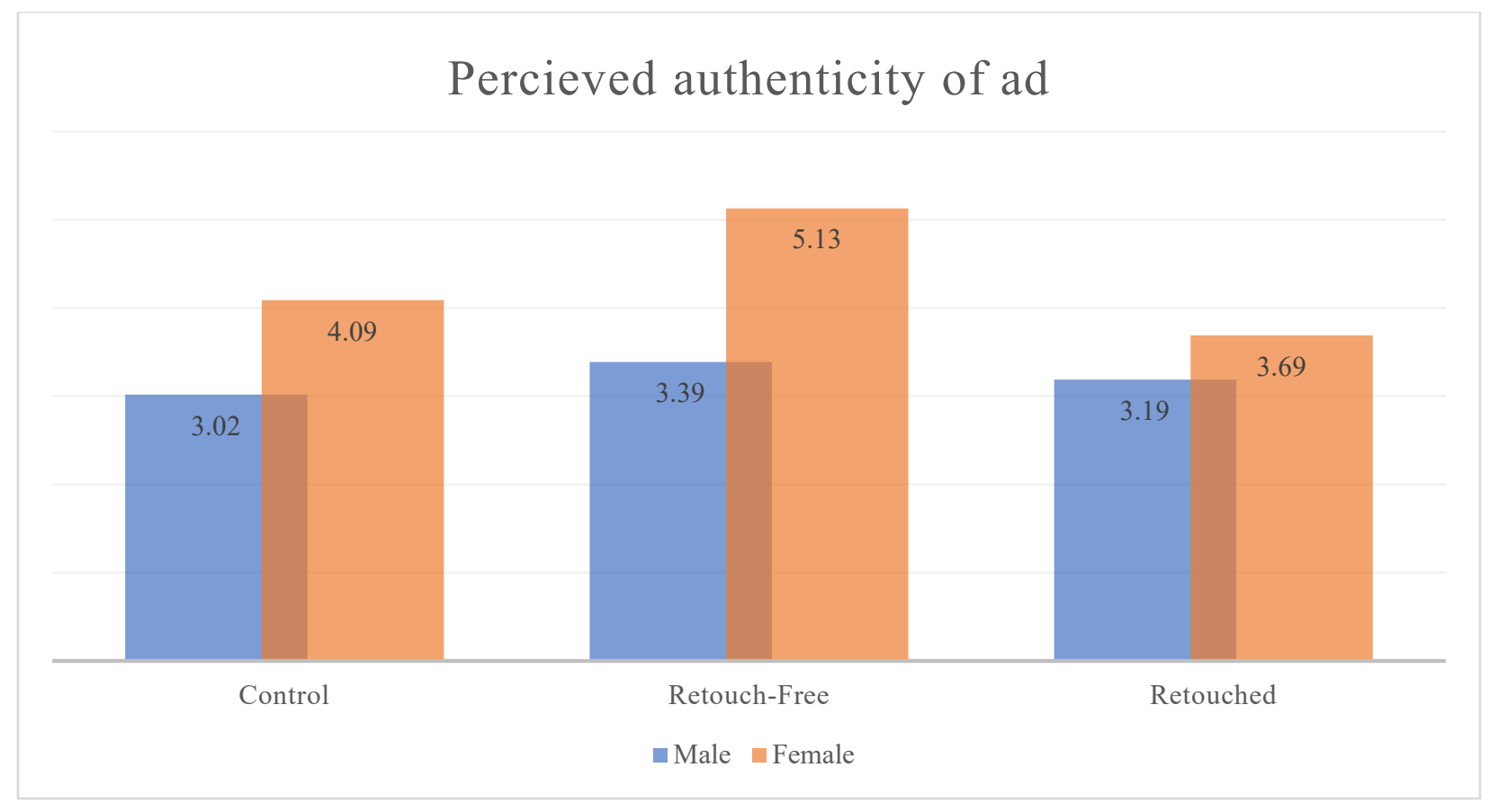

Figure 3. Average perceived authenticity of the ad in male and female participants across the three experimental conditions.

\section{Discussion}

With the male participants, there was no significant variation in mood, self-esteem, or perceived authenticity across the three advertising conditions, because the p-values for each statistical analysis I performed were higher than 0.05 . However, with the female participants, the retouch-free condition did lead to a significant increase $(p=0.012)$ in perceived authenticity when compared to the retouched condition. Essentially, female participants perceived the advertisements labeled with "This model has not been retouched" as significantly more authentic than advertisements labeled with "This model has been retouched". On the other hand, female mood and self-esteem did not significantly increase when exposed to ads with a retouch-free disclaimer, unlike what Cornelis and Peter found in their similar study on young adults (2017). This leads me to conclude that Cornelis and Peter's results on the positive effects of retouch-free disclaimers on mood and self-esteem of young women cannot as of now be generalized to an adolescent population.

The lack of any significant effects of ads in male participants across the three experimental conditions is consistent with multiple previous findings (Grabe et al., 2008, Tiggeman et al., 2014) that show a lack of impact of any type of advertising disclaimer on a male population, and therefore this concept can be generalized to an adolescent population. Furthermore, I found that females perceived all ads (regardless of experimental condition) as significantly more authentic than males did $(\mathrm{t}=-3.69, p=0.0003)$.

\section{Conclusion}

\subsection{Significance}

The intention of my experiment was to evaluate the extent to which retouch-free disclaimers can help lessen negative social comparison in adolescents as they view fashion and beauty advertisements. I found no evidence to show that 
retouch-free disclaimers, or retouched disclaimers for that matter, had any significant impact on adolescent mood and self-esteem, whether positive or negative.

However, this experiment does confirm that adolescent females perceive advertisements with a retouch-free disclaimer as significantly more authentic than they perceive those with no disclaimer. Additionally, it shows that adolescent females are more sensitive than males to the authenticity of ads in general; rating ads significantly higher in terms of perceived authenticity regardless of disclaimer type or even if the ad contains a disclaimer at all. This is valuable knowledge for businesses in the fashion and beauty industries because those who wish to specifically target their ads at an adolescent female audience can utilize this heightened sense of authenticity as they construct their marketing campaigns. In contrast, businesses interested in targeting teenage boys can keep in mind the fact that male adolescents are less sensitive to authenticity as they view ads.

According to the results of this experiment, companies wishing to appeal to an adolescent female audience should not include retouch-free disclaimers with the hope of boosting viewer mood or self-esteem, nor should interested parties view retouch-free disclaimers as a valid way to combat negative social comparison. However, retouchfree disclaimers and retouched disclaimers both had no negative impact on viewers' mood or self-esteem, so including them in ads would theoretically have no negative consequences on these metrics. The only significant benefit of retouch-free disclaimers I found was the increase in perceived authenticity, but it's important to note that this only applies to a female demographic. Advertising campaigns targeting an adolescent male audience should disregard advertising disclaimers in general as a method to manipulate mood, self-esteem, or perceived authenticity, as none of the three experimental conditions had a significant impact on any of these three indicators.

These findings are significant because they justify specifically which theoretical benefits of retouch-free disclaimers are realized in an adolescent female audience, and which are not. It appears that although businesses using retouch-free disclaimers will benefit from the fact that teenage girls will view their ads as more authentic, the teenage girls themselves will not benefit by having their mood boosted or self-esteem increased through upward social comparison. In an age where advertising and product placement is becoming ever more customized to intended audiences through methods like search engine optimization or social media algorithms, my findings are useful in that they further explore the relationship between the at-risk party of adolescent girls and the ads they view on a daily basis.

\subsection{Limitations}

One limitation of this study was the sample size. Cornelis and Peter used a sample size of $>200$ female students, which could not be replicated in the smaller high school institution at which this study took place. However, this sample included both male and female students, which provides valuable insight into if/how male students are affected by different advertising conditions, and the total sample size of both female and male participants was comparable to other studies in this field (Tiggeman et. al, 2014; Convertino et. al, 2016).

Another limitation that made for a less-than-perfect replication of Cornelis and Peter's study was the photos used for the stimulus material. Cornelis and Peter used a photo taken directly from the Aerie REAL campaign, featuring a model wearing undergarments. After consulting with my school's IRB, I determined that this advertisement was not suitable for a teenage audience, the majority of whom would be taking the survey in class. Despite the fact that I tried my best to recreate other aspects of the original ad such as model expression, race, age, and posture, it's possible that the slightly more provocative nature of the original ad could have created different circumstances for social comparison and influenced the effects of the retouched and retouch-free disclaimers on viewers.

\subsection{Future direction for research}

As mine is the first study attempting to examine the effects of retouch-free disclaimers on an adolescent population, further studies should seek to confirm these results for teens aged 14-18 and possibly test the impact of various forms of disclaimers on an even younger population. Further research should also investigate alternative, hopefully more 
successful methods of combating body dissatisfaction due to negative social comparison. Attention should also be paid to male populations, who experience negative social comparison to a lesser extent than their female counterparts but benefit less from body positivity campaigns and societal sympathy in general. As stated earlier, my results seem to suggest that male adolescent populations are unaffected by any type of advertising disclaimer, so alternative methods of lessening social comparison should be researched for this population. It would also be interesting to learn exactly why males have such a different psychological reaction to advertisements, and comparison to their peers, than females.

Another interesting component of how we interact with advertisements is advertising literacy. It would be appropriate for future research to investigate how advertising literacy acts as a mediating factor when it comes to the effectiveness of disclaimers. Millennials and Gen-Z are generally regarded as having high advertising literacy, which would lessen the effects of advertising components such as retouch-free or retouched disclaimers. More knowledge on the effects of advertising literacy, and other related factors such as advertising skepticism (Petrescu et. al, 2019) or internalization of ad-portrayed ideals (Watson et. al, 2011) could help create solutions for negative social comparison that are effective regardless of an adolescent's familiarity with advertising techniques.

In Study 3 of Cornelis and Peter's 2017 paper, they investigate how the realism of the model or subject for social comparison impacts viewer mood and self-esteem. They found that while a retouch-free disclaimer led women to rate their own attractiveness as higher after being exposed to a professional model, it actually caused them to rate other Millennial women similar in appearance to them as less attractive. It would be fascinating to see if these results could also be replicated in an adolescent population, experimenting with not just how adolescents compare themselves to their idols, but also to their peers.

\section{Acknowledgements}

My thanks to Dr. Erlinde Cornelis for her patience and courtesy in answering my questions about her prior research and advice for my own process. I would also like to thank Jill Berge for all her help and support in my AP Capstone journey and high school career-I couldn't have done it without you!

\section{References}

Convertino, Alexandra D., Rodgers, Rachel F., Franko, Debra L., \& Jodoin, Adriana. (2016). An evaluation of the Aerie Real campaign: Potential for promoting positive body image? Journal of Health Psychology, 24(6), 726-737. https://doi.org/10.1177/1359105316680022

Cornelis, Erlinde, \& Peter, Paula C. (2017). The real campaign: The role of authenticity in the effectiveness of advertising disclaimers in digitally enhanced images. Journal of Business Research, 77, 102-112. https://doi.org/10.1016/j.jbusres.2017.03.018

Giorgianni, Francesca, Danthinne, Elisa, \& Rodgers, Rachel F. (2020). Consumer warning versus systemic change: The effects of including disclaimer labels on images that have or have not been digitally modified on body image. Body Image, 34, 249-258. https://doi.org/10.1016/j.bodyim.2020.07.007

Grabe, S., Ward, L. M., \& Hyde, J. S. (2008). The role of the media in body image concerns among women: A metaanalysis of experimental and correlational studies. Psychological Bulletin, 134(3), 460-476. https://doiorg.offcampus.lib.washington.edu/10.1037/0033-2909.134.3.460 
Groesz, Lisa M, Levine, Michael P, \& Murnen, Sarah K. (2002). The effect of experimental presentation of thin media images on body satisfaction: A meta-analytic review. The International Journal of Eating Disorders, 31(1), 116. https://doi.org/10.1002/eat.10005

Harrison, Kristen, \& Hefner, Veronica. (2014). Virtually Perfect: Image Retouching and Adolescent Body Image. Media Psychology, 17(2), 134-153. https://doi.org/10.1080/15213269.2013.770354

Ho-Young (Anthony) Ahn. (2019). College-aged female consumers' meanings of the digitally-enhanced figures in fashion advertising and their interpretations of the Israel's Photoshop Law. Journal of Ethnographic \& Qualitative Research, 14(2), 79-94.

Kerr, K. L. (2010). Sociocultural influences on body image and depression in adolescent girls. Priscilla Papers, 24(2), 21-22.

MacCallum, Fiona \& Widdows, Heather. (2018). Altered Images: Understanding the Influence of Unrealistic Images and Beauty Aspirations. Health Care Analysis, 26(3), 235-245. https://doi.org/10.1007/s10728-016-0327-1

Paraskeva, Nicole, Lewis-Smith, Helena, \& Diedrichs, Phillippa C. (2016). Consumer opinion on social policy approaches to promoting positive body image: Airbrushed media images and disclaimer labels. Journal of Health Psychology, 22(2), 164-175. https://doi.org/10.1177\%2F1359105315597052

Petrescu, Maria, Mingione, Michela, Gironda, John, \& Brotspies, Herbert. (2019). Ad scepticism and retouch-free disclaimers: Are they worth it? Journal of Marketing Communications, 25(7), 738-762. https://doi.org/10.1080/13527266.2018.1437552

Prabhu, S., \& D'Cunha, D. (2018). Comparison of body image perception and the actual BMI and correlation with self-esteem and mental health: A cross-sectional study among adolescents. International Journal of Health \& Allied Sciences, 7(3), 145-149. https://doi.org/10.4103/ijhas.IJHAS 6516

Roeder, A. (2015, March 18). Advertising's toxic effect on eating and body image. Harvard T.H. Chan School of Public Health. https://www.hsph.harvard.edu/news/features/advertisings-toxic-effect-on-eating-and-body-image/

Runfola, Cristin D, Von Holle, Ann, Trace, Sara E, Brownley, Kimberly A, Hofmeier, Sara M, Gagne, Danielle A, \& Bulik, Cynthia M. (2013). Body Dissatisfaction in Women Across the Lifespan: Results of the UNC- SELF and Gender and Body Image (GABI) Studies. European Eating Disorders Review, 21(1), 52-59.

https://doi.org/10.1002/erv.220

Selimbegovic, L., \& Chatard, A. (2015). Single exposure to disclaimers on airbrushed thin ideal images increases negative thought accessibility. Body Image 12: 1-5. https://doi.org/10.1016/j.bodyim.2014.08.012

Taylor, Charles R, Cho, Yoon-Na, Anthony, Carissa M, \& Smith, Danielle B. (2018). Photoshopping of models in advertising: A review of the literature and future research agenda. Journal of Global Fashion Marketing, 9(4), 379398. https://doi.org/10.1080/20932685.2018.1511380

Tiggemann, Marika, Slater, Amy, \& Smyth, Veronica. (2014). 'Retouch free': The effect of labelling media images as not digitally altered on women's body dissatisfaction. Body Image, 11(1), 85-88.

https://doi.org/10.1016/j.bodyim.2013.08.005 
Watson, Stevie, Wells, Cassandra D, \& Hudson, Elania Jemison. (2011). The Effects of Idealized Advertising Imagery on Social Comparisons, Psychological and Emotional Outcomes, and Consumer Vulnerability: A Conceptual Model. Journal of Promotion Management, 17(4), 407-417.

https://doi.org/10.1080/10496491.2011.620494

\section{Appendix A}

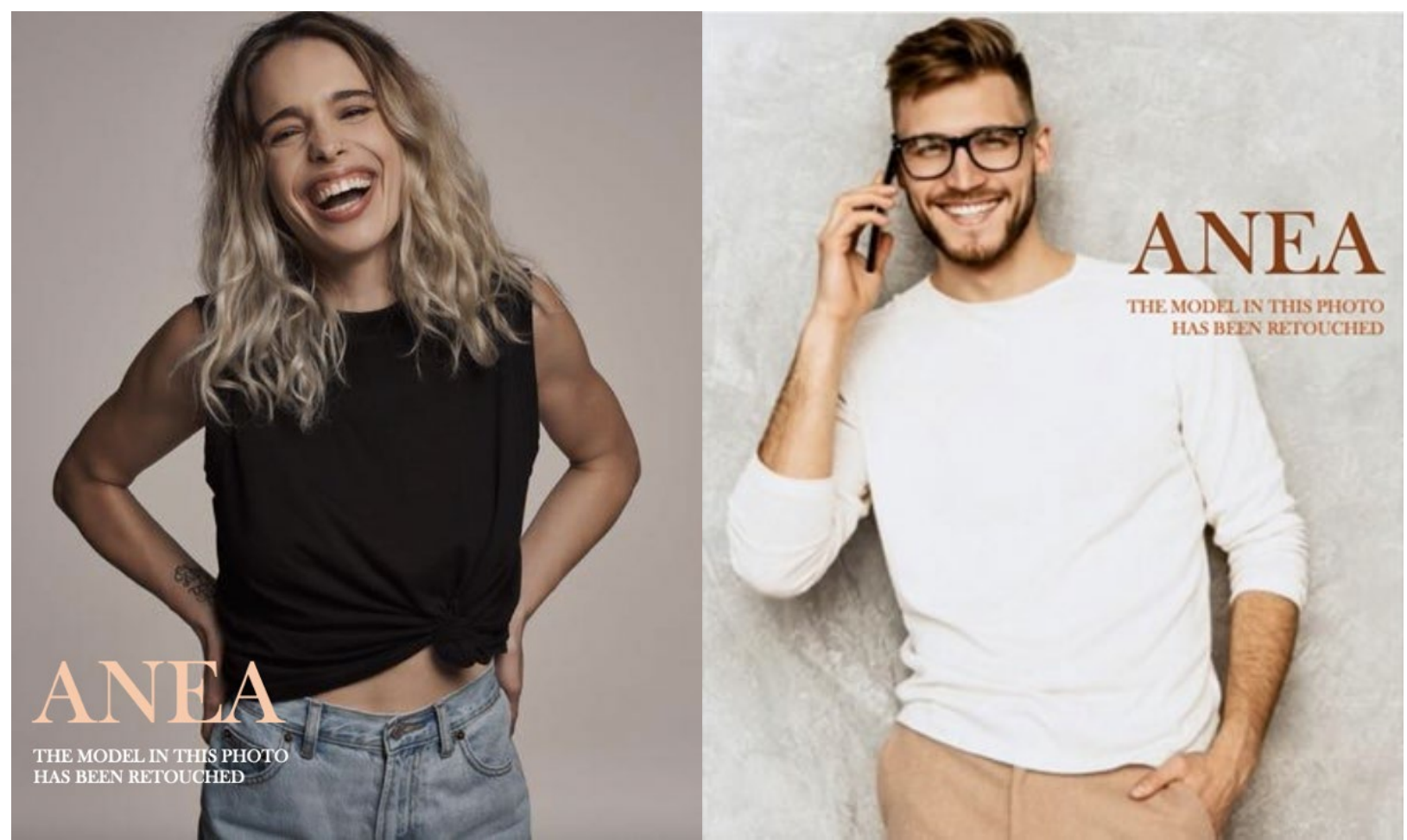

Images 1 \& 2. Advertisements with retouching disclaimers. 


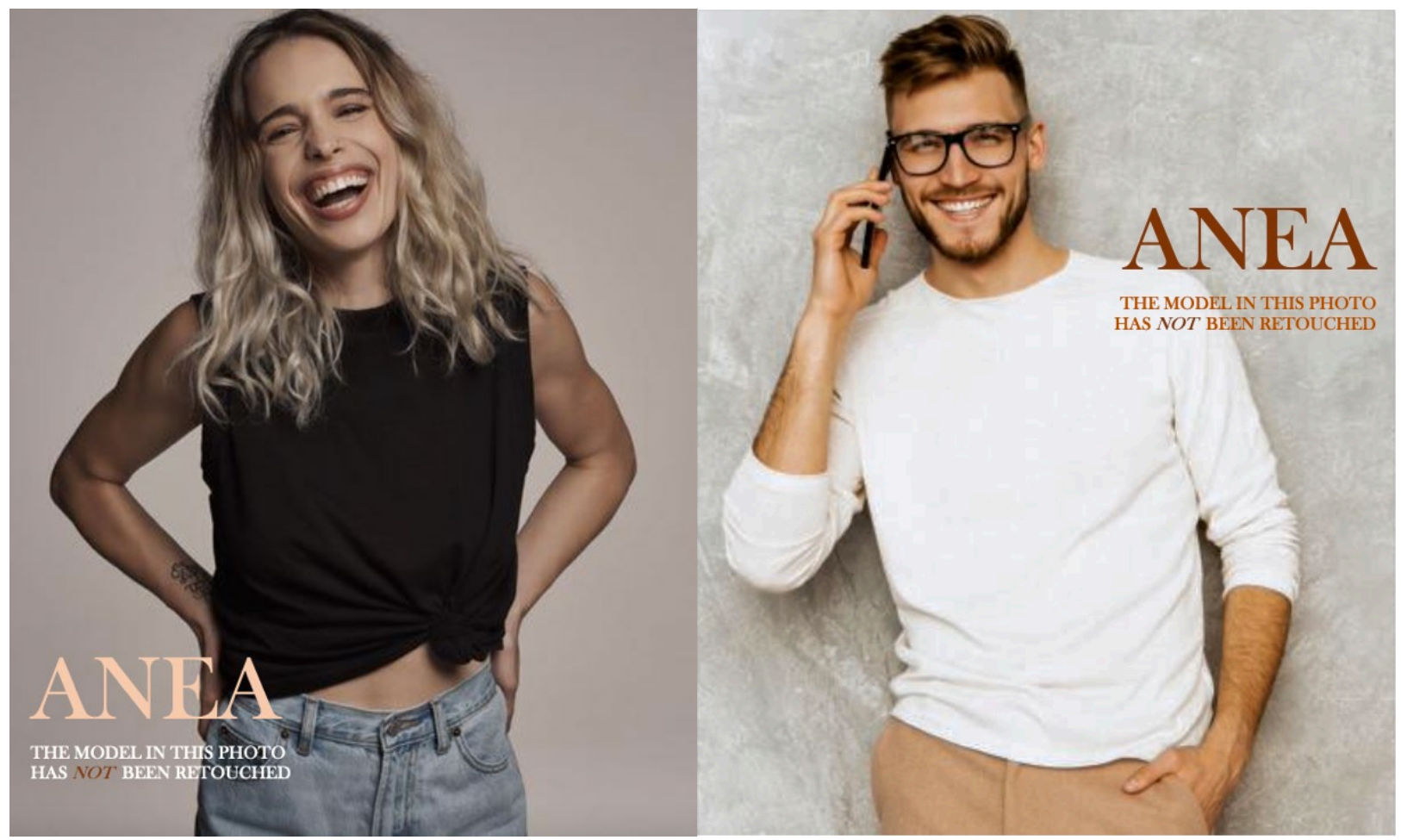

Images $3 \& 4$. Advertisements with retouch-free disclaimers.

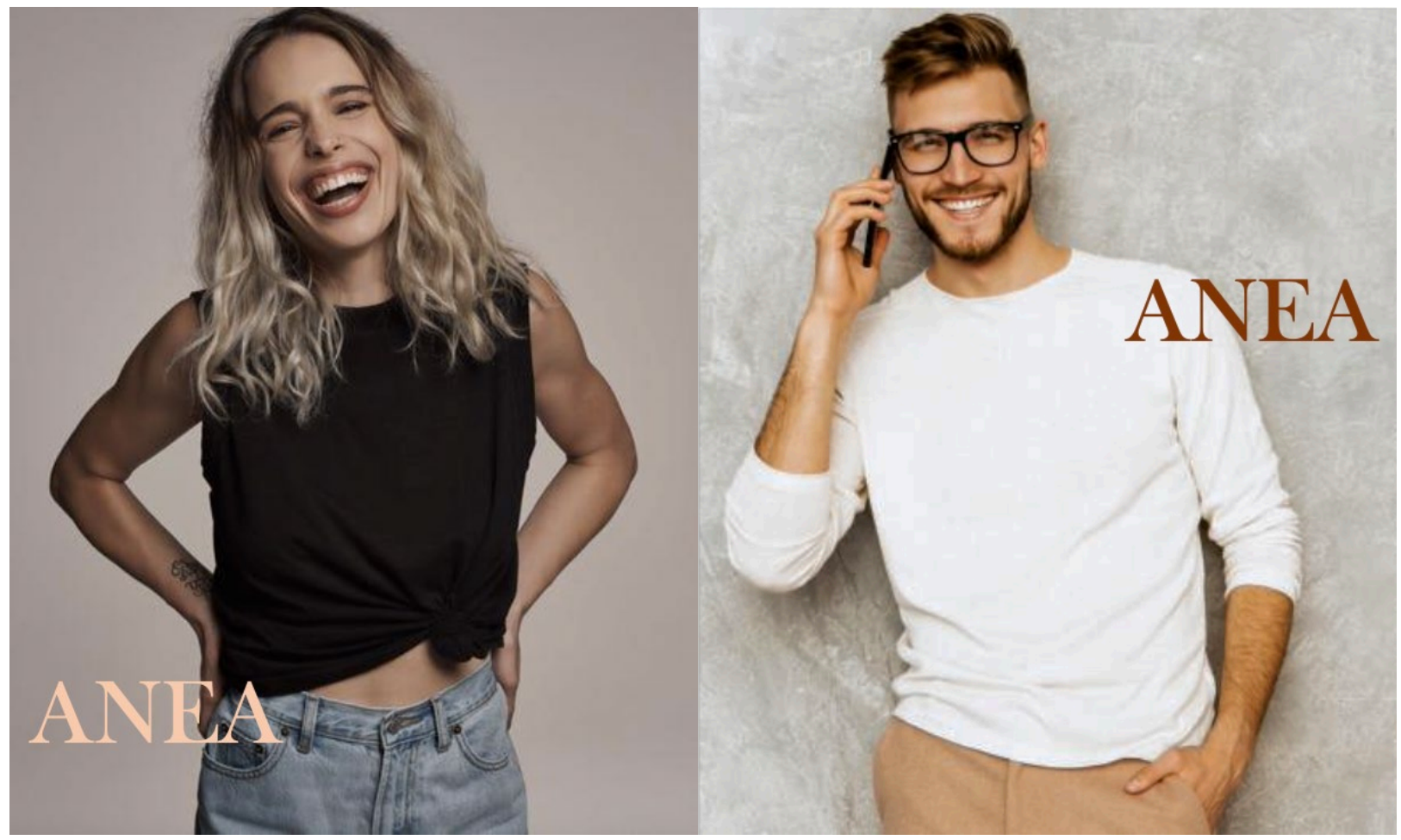

Images 5 \& 6. Advertisements with no disclaimer (control).

Advertisement image sources: https://www.refinery29.com/en-gb/2017/02/142092/chelsea-tyler-modeling-tips-gapnyfw-fall-2017 (female model) and https://www.freepik.com/free-photo/portrait-handsome-smiling-hipster-businessman-model-wearing-casual-summer-white-clothes 6477993.htm (male model) 


\section{Appendix B}

\begin{tabular}{|c|c|c|}
\hline \multicolumn{3}{|c|}{ Pre-exposure survey items } \\
\hline Item \# & Item & Response options \\
\hline 1 & $\begin{array}{l}\text { ELECTRONIC CONSENT: I have read the above } \\
\text { information and I voluntarily agree to participate in } \\
\text { this study. }\end{array}$ & Agree/Disagree \\
\hline 2 & What is your gender? & Female/Male/Other \\
\hline 3 & How old are you? & $14 / 15 / 16 / 17 / 18$ \\
\hline 4 & How happy do you feel right now? & Scale from 0 (not at all) to 10 (extremely) \\
\hline 5 & How confident do you feel right now? & Scale from 0 to 10 \\
\hline 6 & How hopeful do you feel right now? & Scale from 0 to 10 \\
\hline 7 & $\begin{array}{l}\text { I feel that I am a person of worth, at least on an equal } \\
\text { plane with others. }\end{array}$ & $\begin{array}{l}\text { Likert scale (Strongly disagree/Disagree/Neu- } \\
\text { tral/Agree/Strongly agree) }\end{array}$ \\
\hline 8 & I feel that I have a number of good qualities. & Likert scale \\
\hline 9 & All in all, I am inclined to feel that I am a failure. & Likert scale \\
\hline 10 & I am able to do things as well as most other people. & Likert scale \\
\hline 11 & I feel I do not have much to be proud of. & Likert scale \\
\hline 12 & I take a positive attitude towards myself. & Likert scale \\
\hline 13 & On the whole, I am satisfied with myself. & Likert scale \\
\hline 14 & I wish I could have more respect for myself. & Likert scale \\
\hline 15 & I feel useless at times. & Likert scale \\
\hline 16 & At times I think I am no good at all. & Likert scale \\
\hline 17 & I feel good about my body. & Likert scale \\
\hline 18 & On the whole, I am satisfied with my appearance. & Likert scale \\
\hline 19 & The way I look affects how I feel about myself. & Likert scale \\
\hline 20 & I am proud of my body. & Likert scale \\
\hline 21 & $\begin{array}{l}\text { If I could, I would change some things about my } \\
\text { appearance. }\end{array}$ & Likert scale \\
\hline 22 & I often compare my appearance to others'. & Likert scale \\
\hline 23 & I look exactly how I want to. & Likert scale \\
\hline 24 & $\begin{array}{l}\text { When I look in the mirror, I'm happy with what I } \\
\text { see. }\end{array}$ & Likert scale \\
\hline 25 & At times, I think my body isn't good enough. & Likert scale \\
\hline 26 & I feel ashamed of my body. & Likert scale \\
\hline 27 & I am trying to change my body in some way. & Likert scale \\
\hline
\end{tabular}

\begin{tabular}{|l|l|l|}
\hline \multicolumn{2}{|l|}{ Post-exposure survey items } \\
\hline Item \# & Item & Response options \\
\hline 28 & How much do you like the ad? & Scale from 0 (not at all) to 10 (extremely) \\
\hline 29 & $\begin{array}{l}\text { How likely are you to purchase from the brand } \\
\text { (ANEA)? }\end{array}$ & Scale from 0 to 10 \\
\hline 30 & How meaningful is this ad to you? & Scale from 0 to 10 \\
\hline 31 & How authentic does the brand seem? & Scale from 0 to 10 \\
\hline
\end{tabular}

Note: Items 4-27 were also repeated after ad exposure. 